\title{
UMBILICAL ARTERY DOPPLER VELOCIMETRY AND ITS RELATION TO PERINATAL OUTCOME IN NORMAL AND HIGH-RISK PREGNANCIES
}

\author{
Kavya G. Venkatappa1 , K. S. Sowbhagyalakshmi², Shivaprasad ${ }^{3}$, Kavana G. V4, Geetha H. N5 \\ ${ }_{1}^{1}$ Consultant Obstetrician and Gynaecologist and Clinical Embryologist, Department of Obstetrics and Gynaecology, Sarji Hospital, \\ Shivamogga, Karnataka, India. \\ ${ }_{2}^{2} \mathrm{HOD}, \mathrm{OBG}$ and Senior Gynaecologist and Laparoscopic Surgeon, Apollo BGS Hospitals, Mysuru, Karnataka, India. \\ ${ }_{3}^{3}$ HOD, Head and Consultant Radiologist, Apollo BGS Hospitals, Mysuru, Karnataka, India. \\ ${ }^{4}$ Associate Professor, Department of Physiology, Government Medical College, Kannur, Kerala, India. \\ ${ }_{5}^{5}$ Senior Registrar, Department of OBG, Apollo BGS Hospitals, Mysuru, Karnataka, India.
}

\section{BACKGROUND}

\section{ABSTRACT}

Umbilical artery Doppler waveforms provide an estimate of downstream placental vascular resistance and placental blood flow. We wanted to assess the relation between umbilical artery Doppler velocimetry and perinatal outcome in normal and high-risk pregnancies.

\section{METHODS}

The Doppler Ultrasound was performed on 120 pregnant women between 30 and 32 weeks of gestation. Umbilical artery Doppler indices (S/D ratio and RI) were recorded and its relation was assessed with perinatal outcome parameters and analyzed statistically.

\section{RESULTS}

S/D ratio and RI showed significantly higher values in the high-risk group $(4.1,1.2)$ as compared to the control group $(2.4,0.58)$. The mean period of gestation at delivery was $35.28 \pm 1.85$ weeks in high risk group compared to $38.05 \pm 1.03$ weeks in low risk group. Majority of the women $(56.6 \%, \mathrm{n}=34)$ in the control group had spontaneous labour while in the high-risk group, $61.6 \%$ $(\mathrm{n}=37)$ of women underwent LSCS. The mean birth weight of newborns was lower in the high-risk group (2.48 kg) as compared to the control group (3.02 kg). Average birth weight was significantly lower for fetuses with abnormal Doppler velocimetry (S/D ratio) than for those in the normal Doppler group. In the present study, there was higher admission rate of newborns to the NICU and a greater number of newborns required ventilator support in the high-risk group as compared to the control group. Newborns who had NICU stay and required ventilator support showed abnormal S/D ratio of umbilical artery. There were three perinatal deaths in the high-risk group compared to none in the control group.

\section{CONCLUSIONS}

The results of our study support the use of Doppler umbilical artery waveform analysis as an important foetal well-being investigation which though not necessarily diagnostic has a lot of prognostic value.

HOW TO CITE THIS ARTICLE: Venkatappa KG, Sowbhagyalakshmi KS, Shivaprasad, et al. Umbilical artery doppler velocimetry and its relation to perinatal outcome in normal and high-risk pregnancies. J. Evolution Med. Dent. Sci. 2019;8(17):1408-1411, DOI: $10.14260 /$ jemds/2019/313

\section{BACKGROUND}

Perinatal mortality is an important indicator of the quality of obstetric care. Although only $10-30 \%$ of the mothers seen in antenatal period can be classified as high risk, they account for $70-80 \%$ of perinatal mortality and morbidity and therefore high-risk pregnancy requires exemplary individualized care and special attention. The perinatal complications include preterm birth, low birth weight, fetal hypoxia, non-reassuring fetal status and perinatal death. Predicting the risk of these complications may improve the outcome by providing appropriate antenatal surveillance and therapeutic interventions. ${ }^{[1]}$

'Financial or Other Competing Interest': None.

Submission 08-03-2019, Peer Review 10-04-2019,

Acceptance 18-04-2019, Published 29-04-2019.

Corresponding Author:

Dr. Kavya G. Venkatappa,

Consultant Obstetrician and

Gynaecologist and Clinical Embryologist,

No. 418/B, Kanasu First Floor,

Alkola Main Road, Alkola-577201,

Shivamoga, Karnataka, India.

E-mail:dr.kavya.gv@gmail.com

DOI: $10.14260 /$ jemds $/ 2019 / 313$

\section{(c) $\bigcirc$}

The traditional methods of fetal surveillance like nonstress test, fetal heart rate monitoring and fetal biophysical profile are no more ideal tests because of their inability to detect early stages of fetal distress, significant number of false positive tests and low predictive value. Modern science gave us ultrasound which provides a boon for physiological assessment of blood flow in normal and high-risk pregnancies. The development of Doppler ultrasound evaluation of utero-placental and feto-placental circulation is one of the most important achievements of modern obstetrics. [2]

Placental insufficiency is the primary cause (60\%) of intrauterine growth restriction in normally formed fetuses and can be identified using umbilical artery Doppler velocimetry. Umbilical artery Doppler waveforms provide an estimate of downstream placental vascular resistance and placental blood flow. There is a strong association between reduced end-diastolic umbilical artery blood flow velocity and increased vascular resistance in the umbilical placental microcirculation. As well, abnormal umbilical artery Doppler waveforms have been associated with an increased risk of fetal acidosis.[3] 
Many reports have shown a statistically significant relation between increased foetoplacental resistance, as estimated by either the resistance index or systolic-diastolic ratio (S/D), and the later development of either preeclampsia or Intra uterine growth retardation (IUGR).[4] Despite these statistically significant correlations, the clinical utility of umbilical artery Doppler studies has been questioned because of its low predictive values for either preeclampsia or IUGR and other adverse outcome in low risk population. [5] With this background, the present study was undertaken to assess relation between umbilical artery Doppler velocimetry and perinatal outcomes in normal and high risk pregnancies between 30 and 32 gestational weeks.

\section{Objectives of The Study}

1. To evaluate and compare Umbilical artery Doppler indices [Resistance index (RI) and peak systolic frequency/end diastolic frequency shift ratio (S/D ratio)] in normal and high-risk pregnancies.

2. To assess the relation between Umbilical artery Doppler indices and perinatal outcome in normal and high-risk pregnancies.

\section{METHODS}

The present case-control study was carried out on 120 pregnant women between 30 and 32 weeks of gestation reporting on an outpatient basis and also admitted patients to the labour room during the study period. The study was carried out in the department of obstetrics \& Gynaecology and in Department of Radiology, Apollo BGS Hospitals, Mysuru Hospital for a period of one year from May 2015 to May 2016.

Sample selection was based on consecutive sampling. Sixty women with high risk factors were considered as cases and remaining 60 women as controls (Without high risk factors). Singleton pregnancy between 30 and 32 weeks of gestation, voluntary participation in the study, pregnancy with high risk factors which included history of gestational hypertension, pre-eclampsia or eclampsia, intra-uterine growth restriction, anaemia $(\mathrm{Hb}<10.5 \mathrm{gms} / \mathrm{dl})$, diabetes mellitus, maternal age $>35$ years, bad obstetric history were the inclusion criteria considered for the study. Exclusion criteria included multiple pregnancies (more than single fetus), fetal congenital anomalies. Ethical clearance was taken from the Ethical Clearance Committee. After obtaining the informed consent, each study participant was interviewed. Data regarding age, address, past history, obstetric records of the current pregnancy including the investigations done was reviewed.

Doppler indices done between 30 and 32 weeks were recorded. The Doppler Ultrasound was performed by transabdominal examination with a Philips HD11 model, with a 3.5 $\mathrm{MHz}$ (Mega Hertz) convex transducer. Then transducer was placed over anterior abdominal wall over the uterus and was carefully manipulated till a free loop of umbilical cord seen by Grey scale imaging and colour was used to identify the umbilical artery.[6] Waveforms of Doppler ultrasound obtained for umbilical artery was collected and following indices were measured viz. Peak Systolic/diastolic ratio (S/D ratio) and Resistance Index (RI) $=$ Peak systolic flow- diastolic flow/ peak systolic flow. The cut off values (S/D ratio= 3 ,
$\mathrm{RI}=0.65$ ) were considered for Doppler indices of umbilical artery. The values above the cut off values were taken as abnormal for comparison. [7]

All the selected participants were followed up till delivery. Obtained values of umbilical doppler indices was assessed and its relationship with perinatal outcome was analysed in normal and high-risk pregnancies. Deteriorating maternal or fetal conditions were the indications of labor induction. Perinatal outcome parameters were birth weight, ventilator support, NICU (neonatal intensive care unit) stay and perinatal death.

\section{Statistical Analysis}

Descriptive statistical tools such as mean and standard deviation for quantitative variables and frequency, percentage were used for qualitative variables. Inferential statistical tool namely unpaired student's t-test, chi-square test were used. A ' $p$ ' value of $<0.05$ was considered significant. All statistical analysis was done using SPSS software version 21 .

\section{RESULTS}

Present study included 120 pregnant women of 30-32 weeks of gestation. The mean maternal age in cases was significantly higher ( $28.75 \pm 4.25$ years) compared to controls $(26.2 \pm 2.88$ years). There were 6 subjects in high risk group who belonged to elderly age group ( $>35$ years). Thirty two cases $(53.3 \%)$ were primigravida compared to 39 (65\%) in controls (Table 1). The most common high risk factor identified in cases was pre-eclampsia $(n=17)$ followed by IUGR $(n=15)$, diabetes mellitus $(n=10)$, elderly $(n=6)$, history of preterm delivery $(n=6)$, hypothyroidism $(n=3)$, oligohydramnios $(n=3)$ respectively.

Table 1 depicts that the S/D ratio and RI value of the umbilical artery showed significantly higher values in the high risk group as compared to the control group respectively (independent student's t test, p<0.001). Forty two (42) high risk pregnancies had abnormal Doppler indices (S/D ratio and RI) in umbilical arteries compared to 7 in controls $(p<0.001)$. High risk factors namely preeclampsia $\left(\chi^{2}=19.68\right.$ $\mathrm{df}=1, \mathrm{p}<0.001) \&$ IUGR $\left(\chi^{2}=39.33, \mathrm{df}=1, \mathrm{p}<0.001\right)$ had highly significant association with abnormal S/D ratio and RI of umbilical artery.

The mean period of gestation at delivery was $35.28 \pm 1.85$ weeks in high risk group compared to $38.05 \pm 1.03$ weeks in low risk group which showed statistical significance. There were 38 subjects in high risk group who delivered before 37 weeks of gestation compared to four in low risk group. (Table 1).

Majority of the women $(56.6 \%, n=34)$ in the control group had vaginal delivery (Spontaneous Labour) while in the high risk group, $61.6 \%(n=37)$ of women underwent LSCS $\left(\chi^{2}=26.95, \mathrm{df}=2, \mathrm{p}<0.001\right)$.

The mean birth weight of newborns was lower in the high risk group (2.48 kg) as compared to the control group (3.02 $\mathrm{Kg}$ ) and the difference was highly significant. Average birth weight was significantly lower for fetuses with abnormal Doppler velocimetry (S/D ratio) than for those in the normal Doppler group among the cases $\left(\chi^{2}=5.18, \mathrm{df}=1, \mathrm{p}=0.02\right)$. 
In the present study, there was higher admission rate of newborns to the NICU and more number of newborns required ventilator support in the high risk group as compared to the control group. Newborns who had NICU stay $\left(\chi^{2}=5.92, d f=1, p=0.02\right)$ and required ventilator support $\left(\chi^{2}=3.35, \mathrm{df}=1, \mathrm{p}=0.05\right)$ showed abnormal S/D ratio of umbilical artery. There were three perinatal deaths with abnormal Doppler indices in the high risk group compared to none in the control group (p<0.001) (Table 1).

\begin{tabular}{|c|c|c|c|}
\hline & $\begin{array}{c}\text { Cases } \\
\text { (High Risk Group) } \\
(n=60)\end{array}$ & $\begin{array}{l}\text { Controls } \\
(n=60)\end{array}$ & p Value \\
\hline \multicolumn{4}{|l|}{ Maternal Characteristics } \\
\hline $\begin{array}{l}\text { 1. } \quad \text { Mean Age } \pm \text { SD (years) } \\
\text { 2. } \quad \text { Parity: Primigravida (n) } \\
\text { 3. Mode of Delivery (n) } \\
\text { - } \quad \text { Vaginal Delivery (spontaneous) } \\
\text { - } \quad \text { Induced Labour } \\
\text { - } \quad \text { LSCS }\end{array}$ & $\begin{array}{c}28.75 \pm 4.25 \\
32 \\
19 \\
04 \\
37 \\
\end{array}$ & $\begin{array}{c}26.2 \pm 2.88 \\
39 \\
34 \\
16 \\
10 \\
\end{array}$ & $\begin{array}{c}<0.001 \\
0.21\end{array}$ \\
\hline \multicolumn{4}{|l|}{ Doppler indices cut off values (Umbilical artery) } \\
\hline $\begin{array}{ll}- & \text { S/D Ratio (Mean } \pm \text { SD) } \\
\text { - } & \text { RI (Mean } \pm \text { SD) }\end{array}$ & $\begin{array}{l}4.1 \pm 1.18 \\
1.2 \pm 0.37\end{array}$ & $\begin{array}{c}2.4 \pm 0.42 \\
0.58 \pm 0.14\end{array}$ & $\begin{array}{l}<0.001 \\
<0.001\end{array}$ \\
\hline \multicolumn{4}{|l|}{ Perinatal Characteristics } \\
\hline $\begin{array}{ll}\text { 1. } & \text { Mean Gestational Age at Delivery (Weeks) } \\
\text { 2. } & \text { Mean Birth Weight (Kilograms) } \\
\text { 3. } & \text { NICU Stay (n) } \\
\text { 4. } & \text { Ventilator Support (n) } \\
\text { 5. } & \text { Perinatal Death (n) } \\
\end{array}$ & $\begin{array}{c}35.28 \pm 1.85 \\
2.48 \pm 0.34 \\
39 \\
08 \\
03\end{array}$ & $\begin{array}{c}38.05 \pm 1.03 \\
3.02 \pm 0.92 \\
02 \\
00 \\
00\end{array}$ & $\begin{array}{c}0.001 \\
<0.001 \\
<0.001 \\
0.003 \\
0.001\end{array}$ \\
\hline \multicolumn{4}{|c|}{ Table 1. Maternal Characteristics, Doppler Indices of Umbilical Artery and Perinatal Characteristics in Study Population } \\
\hline \multicolumn{4}{|c|}{$\begin{array}{c}\mathrm{SD}=\text { Standard Deviation, } \mathrm{n}=\text { Number of Subjects, } \mathrm{S} / \mathrm{D}=\text { Peak Systolic/Diastolic Ratio, RI= Resistance Index, LSCS= Lateral Segment } \\
\text { Caesarean Section, NICU= Neonatal Intensive Care Unit }\end{array}$} \\
\hline
\end{tabular}

\section{DISCUSSION}

Doppler ultrasound is a non-invasive method of studying the flow velocity within blood vessels. It is uniquely valuable during pregnancy because the development of foetal and maternal placental circulations can be observed. Normal foetal development is dependent on adequate nutrition and oxygenation, and both are dependent on vascular transport. When the maternal or foetal vascular beds do not evolve as expected, significant consequences emerge. Also, when the foetus becomes ill, there are functional changes in the heart and peripheral arterial and venous flow that Doppler can identify. This new technology has enhanced the knowledge of normal and abnormal pregnancies, led to new clinical strategies, and contributed to a reduction in foetal deaths.[7]

The present prospective study showed that Doppler values of the umbilical artery had significantly higher values in the high risk group as compared to the control indicating increased peripheral resistance and consequently decreased diastolic flow leading to foetal compromise. ${ }^{[8]}$

High risk factors namely preeclampsia \& IUGR had highly significant association $(\mathrm{p}<0.0001)$ with abnormal $S / D$ ratio and RI of umbilical artery.

In normal pregnancy there is reduction in the values of various Doppler indices due to the invasion of cytotrophoblast into the spiral arteries leading to the loss of the muscular component, dilatation and uncoiling of these 'uteroplacental' vessels. This results in progressive loss of vascular impedance and increase in end diastolic flow in later half of pregnancy. In pregnancies complicated by hypertension or fetal growth restriction this does not occur and therefore the Doppler indices are higher. ${ }^{[9]}$

This study is in line with similar studies ${ }^{[3,8,10]}$ where in Doppler indices umbilical artery showed higher values in high risk group. Abnormal umbilical artery S/D ratio also showed significant association with PIH, IUGR, oligohydramnios, anaemia and APH. In a study by Bhatt CJ et al (2003), 46\% of hypertensive patients had raised S/D ratio (Greater than 3) in umbilical artery.[11]

Majority of women in the high risk group underwent LSCS thus indicating increased operative intervention in the high risk group based on abnormal Doppler velocimetry. Similar findings were noted in a study carried out by Bansal A et al. [8]

Average birth weight was significantly lower for fetuses with abnormal Doppler velocimetry than for those in the normal Doppler group in the study population. Similar finding was observed by Seyam,[12] where they found that the average birth weight at delivery were significantly lower for foetuses with abnormal Doppler velocimetry than for those in the normal Doppler group.

Newborns who had NICU stay and required ventilator support showed abnormal Doppler indices. Period of gestation at delivery showed significant findings with perinatal outcome parameters such as birth weight, NICU stay and ventilator support i.e. newborns delivered before 37 weeks of gestation required NICU stay, ventilator support and was low birth weight.

All these findings in the present study implied poor perinatal outcome in the presence of abnormal Doppler indices and hence in the presence of foetal anoxia.

\section{CONCLUSIONS}

Doppler ultrasound evaluation reflects foetal haemodynamic status and plays an important role in monitoring high risk pregnancies and thereby helps to determine the optimal time for delivery. The results of our study support the use of Doppler umbilical artery waveform analysis as an important foetal well-being investigation which though not necessarily diagnostic has a lot of prognostic value. The use of Doppler provides information that is not readily obtained from more conventional tests of fetal well-being. 
Doppler velocimetry can be used as a tool for antenatal foetal surveillance as it is a non-invasive test, easy to perform and interpret, significantly predicts the foetal status in utero and perinatal outcome. Thus, in consultation with obstetrician, neonatologist, the timing and mode of delivery can be decided upon the Doppler studies to improve perinatal outcome in high risk cases. Further studies are needed, though, on a multi-centre basis and with larger trials.

\section{ACKNOWLEDGMENTS}

The authors would like to thank study participants who volunteered for the study. Also, we are very grateful to Dr. Binoo Divakaran and Dr Sparshadeep EM for their contribution in study design and statistical analysis. Authors would like to acknowledge the hospital staff for their support rendered in completion of research project.

\section{REFERENCES}

[1] Bharti, Kumar V, Kaur A, et al. Prevalence and correlates of high risk pregnancy in rural Haryana: a community based study. Int Journal of Basic and Applied Medical Sciences 2013;3(2):212-7.

[2] Gupta S, Misra R, Ghosh UK, et al. Comparison of foetomaternal circulation in normal pregnancies and pregnancy induced hypertension using color Doppler studies. Indian J Physiol Pharmacol 2014;58(3):21-4.

[3] Gagnon $R$, Van den Hof $M$, Diagnostic Imaging Committee, et al. The use of fetal Doppler in obstetrics. J Obstet Gynaecol Can 2003;25(7):601-14.

[4] Fleischer A, Schulman H, Farmakides G, et al. Umbilical artery velocity waveforms and intruterine growth ratardation. Am J Obstet Gynaecol 1985;151(4):502-5.
[5] Abramowicz JS, Warso SL, Sherer DM, et al. Value of a random single Doppler study of the umbilical predicting preinatal outcome. J Ultrasound Med 1991;28:327-30.

[6] Malik R, Saxena A. Role of colour Doppler indices in the diagnosis of intrauterine growth retardation in high-risk pregnancies. Journal of Obstetrics and Gynaecology of India 2013;63(1):37-44.

[7] Schulman H. Doppler velocimetry of fetal and maternal vessels. In: Sabbagha ER. Edr. Diagnostic ultrasound applied in obstetrics and gynecology. $3^{\text {rd }}$ edn. Philadelphia: Lippincott Company 1994: p. 241-2.

[8] Bansal A, Choudhary J, Gupta H. Role of panvessel Doppler study in high risk pregnancy. Journal of Dental and Medical Sciences (IOSR-JDMS) 2015;14(2):90-3.

[9] Gupta U, Qureshi A, Samal S. Doppler velocimetry in normal and hypertensive pregnancy. Internet J Gynecol \& Obstet 2008;11(2):123-6.

[10] Urmila S, Beena B. Triple vessel wave pattern by Doppler studies in normal and high risk pregnancies and perinatal outcome. J Obstet Gynecol India 2010;60(4):312-6.

[11] Bhatt CJ, Arora J, Shah MS. Role of color Doppler in pregnancy induced hypertension (a study of 100 cases). Indian J Radiol Imaging 2003;13(4):417-20.

[12] Seyam YS, Al-Mahmeid MS, Al-Tamimi HK. Umbilical artery Doppler flow velocimetry in intrauterine growth restriction and its relation to perinatal outcome. Int J Gynaecol Obstet 2002;77(2):131-7. 